Article

\title{
Wearable E-Textile Technologies: A Review on Sensors, Actuators and Control Elements
}

\author{
Carlos Gonçalves 1,2,*(i) , Alexandre Ferreira da Silva ${ }^{3}$ (iD) , João Gomes ${ }^{2}$ and Ricardo Simoes ${ }^{1,4}$ (iD) \\ 1 Institute for Polymers and Composites IPC/I3N and MIT-Portugal Program, University of Minho, \\ 4800-058 Guimarães, Portugal; rsimoes@dep.uminho.pt \\ 2 Center of Nanotechnology and Smart Materials (CeNTI), 4760-034 VN Famalicão, Portugal; jgomes@centi.pt \\ 3 Center for Micro Electro Mechanical Systems (CMEMS-UMinho) and with the MIT Portugal Program, \\ University of Minho, Campus of Azurem, 4804-533 Guimaraes, Portugal; asilva@dei.uminho.pt \\ 4 Polytechnic Institute of Cávado and Ave (IPCA), 4750-810 Barcelos, Portugal \\ * Correspondence: cgoncalves@centi.pt; Tel.: +351-252-104-152
}

Received: 26 December 2017; Accepted: 2 March 2018; Published: 6 March 2018

\begin{abstract}
Wearable e-textiles are able to perform electronic functions and are perceived as a way to add features into common wearable textiles, building competitive market advantages. The e-textile production has become not only a research effort but also an industrial production challenge. It is important to know how to use existing industrial processes or to develop new ones that are able to scale up production, ensuring the behavior and performance of prototypes. Despite the technical challenges, there are already some examples of wearable e-textiles where sensors, actuators, and production techniques were used to seamlessly embed electronic features into traditional wearable textiles, which allow for daily use without a bionic stigma.
\end{abstract}

Keywords: e-textiles; digital textiles; smart textiles; conductive yarns; heat regulating textiles

\section{Introduction}

Nowadays, the wearable e-textile technologies are facing an exponential growth. Day by day new textiles come to the market with functionalities such as: heat regulation, luminescent, touch, and sensitivity. Those functionalities are useful for several applications in different fields such as: healthcare, sports, space exploration, and gaming. The gaming industry revenue using wearable e-textile technologies is growing, resulting in $\$ 66$ billion in 2013 for the mobile games on smartphones and tablets, and the growth in 2017 was estimated at around $\$ 78$ billion [1]. The increasing miniaturization of electric circuits enables seamless incorporation of functionalities, which helps to avoid a potential bionic stigma and to embrace market penetration of wearable e-textiles.

The potential of electronic wearable textiles has been perceived by several companies, like Google, among others, which is developing capacitive touching textiles in its project, called Google Jacquard. This project enables a seamless and reliable wearable computing concept that can help costumers to perform daily tasks like answering phone calls without stopping an ongoing activity [2].

The main wearable e-textiles have embedded capacitive, resistive, and optical sensors allowing the textile to sense touch, strain, pressure, temperature, and humidity. The sensors are normally connected to control boards responsible to process information.

Several review works have been published summarizing developments in wearable e-textile technologies [3-6]. A variety of sensing and output devices have been used into e-textiles using touch sensitive buttons [7], pressure sensors [5], Radio Frequency Identification (RFIDs), or electrocardiography (ECG) sensors in electronic socks and sports bras [8]. Moreover, electromyography (EMG) sensors are used to control active orthotics $[9,10]$, prostheses, mobility assistive devices [11] and provide electrical stimulation [12]. Accelerometers have been used in 
e-textiles to access fall risks [13] and to monitor functional ability at home. Output devices used Light Emission Diode (LED) arrays, thermo chromic ink, vibration, and shape memory alloys [4].

The most common communication methods for interactive textiles are Wi-Fi and Bluetooth with a hybrid approach to power. All of the wearable e-textiles have battery requirements that must be fulfilled either by detachable batteries or by thin, flat, and flexible batteries that are able to survive washing, drying, ironing, and dry cleaning [14].

In this paper, it is presented a review of wearable e-textile technologies. The paper is structured as follows:

- First materials, connections and fabrication methods are explained in the context of wearable e-textile technologies; and,

- Secondly, textile capacitive and resistive sensors are explained, highlighting measurement ranges and fabrication methods. Examples of commercial wearable e-textiles are presented and shortly described.

- Finally, a conclusion is done mentioning the importance of wearable e-textile technologies with a small future perspective.

\section{Materials, Connections and Fabrication Methods}

The wearable e-textiles can be made with several materials using different fabrication methods. The selected materials and fabrication methods are always interconnected with the final application. This makes e-textile a multidisciplinary research field, with the need of expertise in several fields, such as textile, materials, electronics, mechanics, and computer engineering [15].

\subsection{Adapted Fabrics: E-Textiles Fabrication Methods}

Over the past decade, it has been proved that traditional fabrication methods that are used to produce conventional textiles could be used in e-textiles production too. The development of flexible conductive yarns with diameters that are similar to the conventional textile yarns enable the use of traditional fabrication methods to merge conductive threads with non-conductive threads. The conductive yarns incorporation processes into conventional textiles threads can be manually done by sewing conductive yarns [9] or automatically through embroidery [16], weaving [17], knitting [18], and breading machines [14].

Coating non-conductive yarns with metals, galvanic substances or metallic salts can also be used to make electrical conductive yarns from pure textile threads, which also enables an e-textile production. Common textile coating processes include electroless plating [19], chemical vapor deposition [20], sputtering [21], and with a conductive polymer coating [15].

Stamping conductive inks is also an alternative to embed conductive lines into textiles. There are several technologies that can print conductive material on textile substrates, but all of them use conductive inks with high conductive metals, such as silver $(\mathrm{Ag})$, copper $(\mathrm{Cu})$, and gold $(\mathrm{Au})$. Table 1 shows a list of manufacturing techniques with a qualitative comparison of fabrication attributes. All of the manufacturing techniques can be used to produce e-textiles.

Table 1. Qualitative comparison of e-textiles fabrication atributes.

\begin{tabular}{ccccc}
\hline E-Textile Manufacturing Technique & Machinery Costs & Material Costs & Process Complexity & Resistance to Wear \\
\hline Embroidery & High & Low & High & High \\
Sewing & Low & Low & Low & High \\
Weaving & Low & High & High & High \\
Non-woven & Low & Low & Low & Low \\
Knitting & Low & High & High & Low \\
Spinning & Low & Low & Low & Low \\
Breading & Low & Low & Low & Low \\
Coating & High & Low & Low & Low \\
Printing & High & High & \\
\hline
\end{tabular}


Connections to data acquisition systems are achieved by either mechanical [15] or electrical mechanisms [22]. This way, textile structure platforms as woven, knitted, or nets can be used to produce e-textiles, avoiding attaching electronics to textile substrates.

\subsection{Electrical Components}

The wearable e-textiles would not be possible without electrical components, such as electrodes, connectors, and interconnectors. When wearable e-textiles are used for the acquisition of electrical biological signals such as electrocardiogram (ECG), the electrodes are the bridge between the body and the circuit. When there is no need of electrical signal acquisition, there is still the need of connectors and interconnectors in order to bridge the textile with the electronics.

Copper wire can be used in applications without skin contact, and silver thread can be used in applications that requires direct contact with skin [23]. The energy needed to power e-textile circuits is normally provided from Lithium Polymer (LiPo) batteries. The LiPo batteries are selected accordingly to a tradeoff between power autonomy and battery size. The goal is to select the smallest LiPo battery that is able to supply the e-textile circuit power demands during a predefined amount of time. There are also research projects developing energy harvesting solutions that are embedded into e-textiles [24]. With energy harvesting solutions, it is possible to charge small LiPo batteries, keeping the e-textile energy demands during use. Figure 1 shows some examples of the connection techniques that are used in e-textile circuits and transducers.

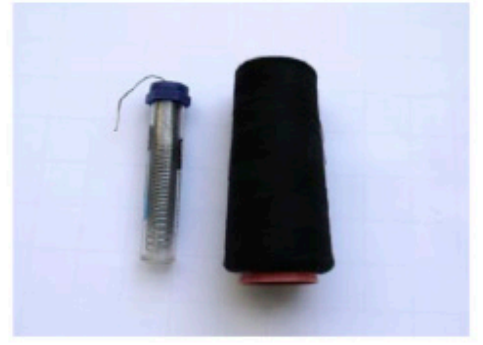

(a)

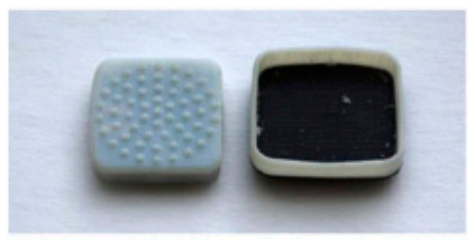

(d)

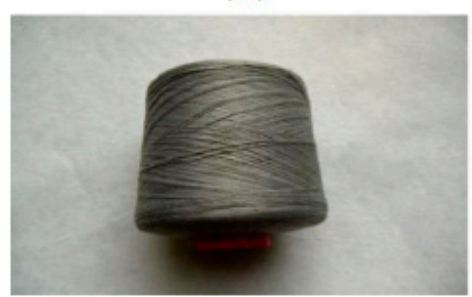

(g)

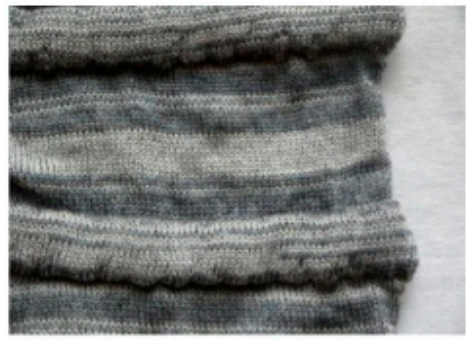

(b)

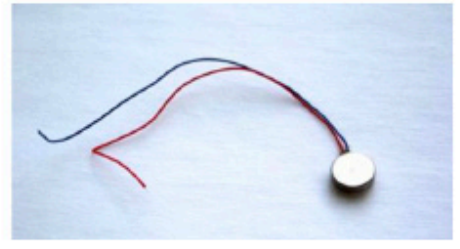

(e)

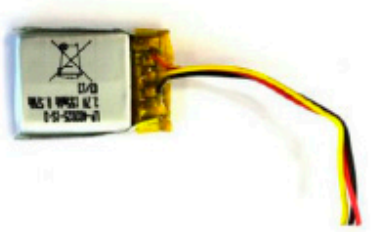

(h)

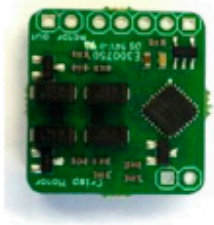

(c)

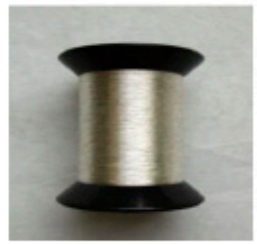

(f)

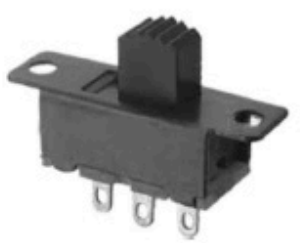

(i)

Figure 1. Textile and electronic materials used in e-textiles. (a) Solder and polyester thread used into e-textiles; (b) E-textile capacitor; (c) Printed Circuit Board (PCB) for e-textiles; (d) Casing shell for e-textiles; (e) Vibration motor; (f) Elektrisola textile conductive wire; (g) Bekintex conductive thread; (h) Lithium-ion battery used to power e-textiles; and, (i) Slide switch used to switch On/Off e-textiles [25]. 
The two main bond categories for connectors and interconnects are mechanical and physical. Mechanical connections are made with snaps that are directly pressed into conduction lines, and are normally made when there is a need to detach any electrical module from the e-textile. Physical connections include microwelding, thermoplastic adhesion [26], mixed conductive polymer adhesion [27], joint soldering, and electroplating [28]. Physical connections are made when there is a need for a permanent connection. E-textile connectors remain an open research field due to the diversity of application environments where each solution is customized and is almost unique.

\subsection{Textile Circuitry}

Textile circuits are electrical circuits built on textile substrates. Embroidery conductive thread into textile substrates is a widely used technique. This technique is used to stitch patterns that define circuit traces, component connection pads or sensing surfaces using Computer Assisted Design (CAD) tools [29]. The conductive patterns can also be done using inkjet-printed techniques of graphene-based conductive inks [30]. Normally a textile circuit is designed to have a low power consumption rate and high input impedance, which is opposite to the conventional requirement of low impedance for component interconnections.

Many yarns available in the market can be used for connections and circuit elements. These include silverized yarns, stainless steel thread, titanium, gold, and tin.

Another technique to fabricate textile circuits is to iron a welded circuit to the textile substrate [31]. Once the circuit is attached to the textile, it can be soldered like a traditional printed circuit board.

There are also commercial printed control boards made to be wearable. Table 2 shows a qualitative attribute comparison from a list of wearable control boards that are available in the market. According to the information presented at Table 2, Xadow is the best wearable control board that is available in the market due to the analog/digital pins and the wireless communication in board. The possibility to be washed is also an important advantage that enables a permanent connection with a textile and textile fibers.

Table 2. Atribute comparisson of wearable control boards [32].

\begin{tabular}{ccccc}
\hline Control Boards & Washable & Analog Pins & Digital Pins & Wireless Communication \\
\hline Lilypad & Yes & Yes & Yes & No \\
Intel Edison & Yes & Yes & Yes & Yes \\
Flora & Yes & No & Yes & No \\
Xadow & Yes & Yes & Yes & Yes \\
SquareWear & Yes & Yes & Yes & No \\
Printoo & Yes & Yes & Yes & No \\
BITalino & Yes & Yes & Yes & No \\
Igloo & Yes & Yes & Yes & No \\
WaRP7 & No & Yes & Yes & Yes \\
nRF52832 & No & Yes & Yes & Yes \\
\hline
\end{tabular}

Flexible conduction lines could also be made of any conductive ink and conductive polymer. Thick and thin printing processes are two production techniques that are used to print conductive inks. An example of a thick film process is silk screening, where an adhesive conductive ink is applied to the open areas of a textile mesh allowing for the ink to penetrate into the fabric [33]. A sputtering process can also be used to produce high-resolution circuits on textile substrates. The textile substrate, kept at $150{ }^{\circ} \mathrm{C}$, needs to be placed in a vacuum chamber with an inert gas like argon and a shadow mask to make the circuit patterns. There are also research projects reporting the use of nanosoldering methods to produce e-textiles with carbon nanotubes (CNT) conductive lines. The CNTs are soldered onto the fiber surface of non-woven fabric by ultrasonication, which brings a strong adhesion between the carbon nanotubes and the textile fibers. The CNTs do not detach when the e-textile is under vigorous mechanical stirring, or even after being washed [34]. 


\subsection{Textile Circuit Elements}

Textile circuit elements can be built to be adapted to the textile substrates. Small electric components can be sewn into the conductive lines on fabrics [35] either directly or using sockets attached to the fabric with connection resistivity that is lower than $1 \Omega$ [36]. Gripper snaps and textile switches can also be used in order to ensure connectivity, allowing strong connections [37].

Electronic elements can be made out of conductive thread by sewing thread fibers in patterns, with multiple crossings, to achieve desired electrical properties. Conductive properties can be given to threads by several techniques before and after the thread manufacturing process [38].

Another very common technique entails the application of metal or conductive polymer coatings to the textile substrate. Laminating techniques are also used, including those that are adapted from conventional and flexible electronics [39]. With those techniques, passive elements can be formed with conductive inks and polymers. Resistors (i.e., $2-8 \Omega / \mathrm{mm}$ ), capacitors (i.e., $1 \mathrm{pF}$ to $1 \mathrm{nF}$ ), and inductors (i.e., $500 \mathrm{nH}$ to $1 \mu \mathrm{H}$ at $10 \mathrm{MHz}$ ) can be made by planar printing techniques, such as screen printing or sputtering metal inks onto fabric substrates, such as cotton, polyester, silk, wool, polyacrylonite, and fiberglass fabrics [33]. It has also been shown that resistive elements can be made by adjusting the dimension of an already coated conductive polymer fabric [40]. In the case of transistors, the core of a metalized yarn can be used as gate, while source and drain contacts can be made by depositing metals or polymers using evaporation or soft lithography processes [41]. Transistors can also be fabricated on strips of Kapton and be later interlaced into a textile substrate [42]. Figure 2 shows a textile electrode suitable for acquiring biological signals, such as ECG.

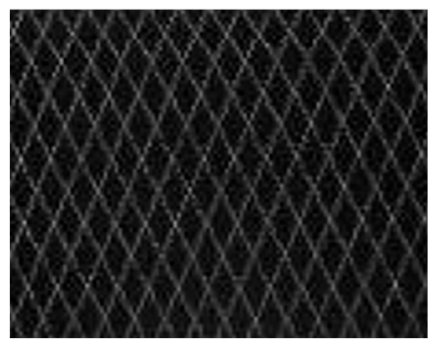

Figure 2. Textile electrode used to sense biological signals such as electrocardiography [43].

\section{Smart Fabrics Sensors}

\subsection{Capacitive Pressure Sensors}

Usually, capacitive pressure sensors are made on textiles that can be sewn, snapped, or glued to a fabric substrate and welded to other electronics or wires. Textile capacitors can also be made from compliant conductive materials that are acting as conductive plates separated by dielectrics. The conductive plates can be woven [28], sewn [44], and embroidered with conductive thread/fabrics, or they can be painted, printed, sputtered, or screened with conductive inks [45], or conductive polymers [46]. The dielectrics used are typically synthetic foams, fabric spacers, and/or soft non-conductive polymers. Capacitive fibers can also be manufactured using techniques that are similar to those found in flexible electronics, such as a silicon fiber sputtered with metals [47].

The capacitance of a capacitive pressure sensor depends on the area of two conductive parallel plans, the conductive material and the distance between each other. Keeping the same area for the conductive plates the capacitance will change with the distance between them. When the distance between the conductive plates decreases, the capacitance increases, and when the distance between the conductive plates increases, the capacitance decreases. Table 3 presents a list of production techniques used to produce capacitive pressure sensors. From Table 3, it is possible to see that the conductive element and production technique influence not only the pressure range measurement but also measurement sensitivity. Embroidery of conductive thread into textile substrates produces 
capacitor pressure sensors with low resolution that are good to make seamless e-textile press buttons. The Crosslite ${ }^{\mathrm{TM}}$ capacitor production technique is able to produce capacitive pressure sensors with higher resolutions that can be used sense pressures over time.

Table 3. Fabric capacitor pressure sensor production techniques [48].

\begin{tabular}{|c|c|c|c|c|c|}
\hline $\begin{array}{l}\text { Production } \\
\text { Technique }\end{array}$ & Elements & $\begin{array}{l}\text { Measured } \\
\text { Variable }\end{array}$ & Sensitivity & Pressure & Size \\
\hline Embroidery & Conductive thread & Electrical contact & $\begin{array}{l}\text { Switching } \\
\text { threshold }\end{array}$ & Contact sensing & $\mathrm{mm}^{2}-\mathrm{cm}^{2}$ range \\
\hline $\begin{array}{l}\text { Patterned } \\
\text { electrodes }\end{array}$ & Conductive ink & $\begin{array}{l}\text { Thickness } \\
\text { compression }\end{array}$ & $0.214 \mathrm{~V} / \mathrm{pF}$ & $0-13 \mathrm{kPa}$ & $32 \mathrm{~mm}^{2}$ \\
\hline $\begin{array}{l}\text { Laminated } \\
\text { electrodes }\end{array}$ & $\begin{array}{c}\text { Thin film } \\
\text { deposited metals }\end{array}$ & $\begin{array}{c}\text { Capacitance at } \\
\text { intersecting points }\end{array}$ & $0.01 \Delta \mathrm{C} / \mathrm{mN}$ & $0-50 \mathrm{~N} / \mathrm{cm}^{2}$ & Diameter $=250 \mu \mathrm{m}$ \\
\hline $\begin{array}{l}\text { 3D textile } \\
\text { capacitor }\end{array}$ & $\begin{array}{c}\text { Conductive fabric } \\
\text { 3D textile }\end{array}$ & $\begin{array}{l}\text { Thickness } \\
\text { compression }\end{array}$ & $2 \mathrm{pF} / \mathrm{N} / \mathrm{cm}^{2}$ & $0-0.75 \mathrm{~N} / \mathrm{cm}^{2}$ & $9 \mathrm{~cm}^{2}$ \\
\hline
\end{tabular}

\subsection{Resistive Pressure Sensors}

The resistive pressure sensors have a correlation between pressure and electrical resistance. These sensors can be made of different conductive materials in different structures using different production techniques. The variable resistive materials can be sewn, embroidered or glued to the textile substrate to measure pressure. The working principle of a resistive pressure sensor is based on an electric resistance that increases when the resistive material is stretched or compressed. According to Ohm's Law $\left(V=R^{*} \mathrm{I}\right)$, for the same electric current, a higher resistance makes the output voltage increase. This way, the stretch or compression can be correlated to the sensed voltage [49]. Table 4 shows a list of textile production techniques that are used to produce textile pressure sensors. The conductive material and production technique influence the sensitivity and sensed pressure range.

Table 4. Textile pressure sensors based on resistive mechanism [48].

\begin{tabular}{cccccc}
\hline Production Technique & Elements & Sensitivity & Pressure range & Size & Characteristics \\
\hline Switch tactile sensor & Plated fabric Cu, Ni & $\begin{array}{c}\text { Threshold at } \\
500 \mathrm{~g} / \mathrm{mm}^{2}\end{array}$ & $70-500 \mathrm{~g} / \mathrm{mm}^{2}$ & $8 \mathrm{~mm}^{2}$ & Active sensing cells \\
\hline Tooth structured & Conductive fabric & $2.98 \times 10^{-3} \mathrm{kPa}^{-1}$ & $-2000 \mathrm{kPa}$ & $760 \mathrm{~mm}^{3}$ & $\begin{array}{c}\text { Strain in under } \\
\text { pressure fabric }\end{array}$ \\
\hline $\begin{array}{c}\text { Polyurethane foam } \\
\begin{array}{c}\text { Conductive Rubber } \\
\text { based }\end{array}\end{array}$ & PPyPolyurethane & $0: 0007 \mathrm{mS} / \mathrm{N}$ & $1-7 \mathrm{kN} / \mathrm{m}^{2}$ & $4 \mathrm{~cm}^{3}$ & $\begin{array}{c}\text { Conductance increases } \\
\text { with compression }\end{array}$ \\
\hline QTC-Ni based & Pressure composite & $\begin{array}{c}\sim 10^{6} \Omega / 1 \% \\
\text { compression }\end{array}$ & $25 \%$ compression & Diameter $=5.5$ mm & $\begin{array}{c}\text { Resistance changes } \\
\text { with applied load }\end{array}$ \\
\hline
\end{tabular}

\subsection{Optical Textile Sensors}

The working principle of optical textile sensors is based on the variation of the light intensity or the amplitude that can be sensed by a fiber Bragg grating (FBG) sensor. These type of sensors were first developed in 1978 by Hill et al. when the photosensitivity in optical fibers were found [50]. Since then, several configurations were developed and incorporated into fabrics [51,52]. The small glass optical fibers diameters (in the microns range) make these materials suitable for seamless textile integration with industrial processes. The optical fiber light source can be a small light emission diode (LED), and the light amplitude at the end of the optical fiber can be sensed with a small photodetector. Depending on the textile movements, the light amplitude will change allowing to sense textile displacements 
and pressures. The optical textile sensors can be used to sense textile displacements and pressures in applications where the electrical currents cannot cross textile substrates. Figure 3 shows a schematic of a fabric with optical fibers incorporated. When the elastic fabric is stretched, the light amplitude passing thought the fiber increases, which increases the output voltage coming out the photodetector.

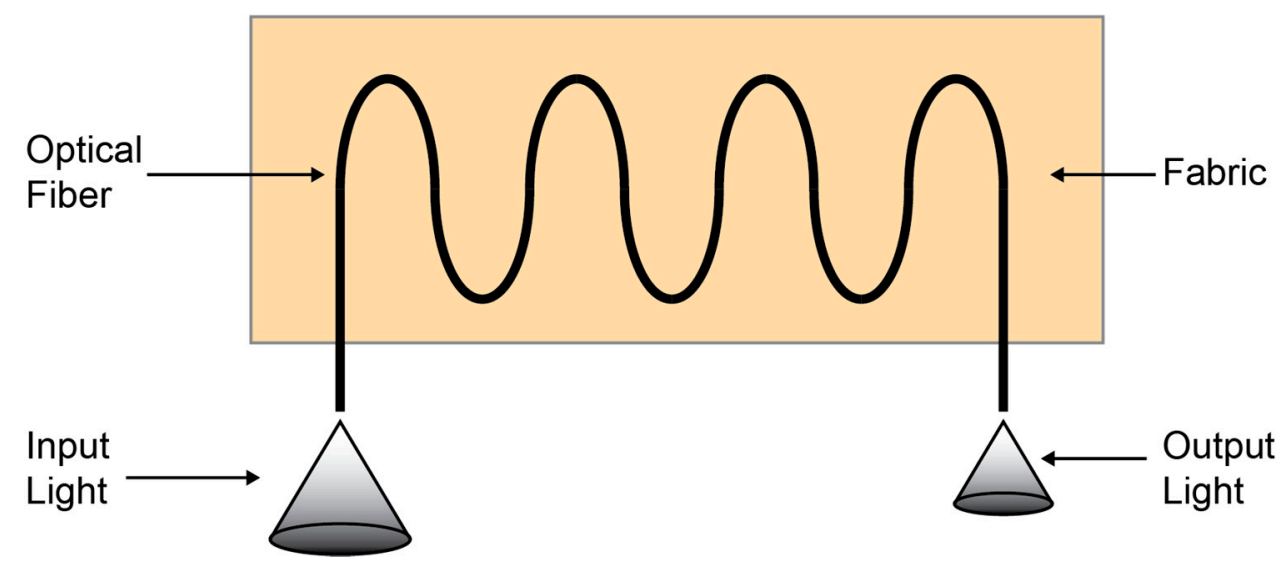

Figure 3. Schematic of a fabric with optical fibers incorporated.

\subsection{Temperature and Humidity Sensitive Textile}

There are several possibilities to build an e-textile to sense temperature and humidity changes. Resistance and capacitance are the main principles to build humidity textile sensors. The resistive humidity textile sensors answer to moisture variation by changing its conductivity, while the capacitive humidity textile sensors answer to water vapor by varying its dielectric constant [53]. Combinations of polymer/substrate; PEDOT-PSS/PAN nanofibers [48], PEDOT-PSS/polyimide, PEDOT [54] - PSS/lycra tactel and Polypyrrole, are sensitive to humidity changes by changing their electrical conductivity [44]. These sensitized substrates can also be woven into textiles. Polymers that are suitable for capacitive humidity sensors include polyethersulfone (PES), polysulfone (PSF), and divinyl siloxane benzocyclobutene (BCB). Other humidity sensing devices have flexible transistors that changes conductivity with the humidity levels [55]. Coated sensors on fabrics typically react to humidity if they are organic or carbon based.

Temperature sensors compatible with fabrics can be made on flexible substrates, such as plastics and polyimide sheets. These sensors can be later attached to fabrics or integrated into their structure. Resistance temperature detectors (RTDs) have elements, such as platinum/nichrome (NiCr) and related materials that can be coated on flexible surfaces. Kapton based plastic stripes of platinum RTDs can be woven into fabrics to manufacture a temperature sensitive textile [56]. A gold RTD has been manufactured on a flexible polyimide substrate [57]; its resistance changes linearly with temperature. Thermoelectric generators can also be attached to fabrics using molding techniques and fabric connection technologies [58]. All of the conductive polymers and carbon based conductive particle polymers have a temperature dependent response. For instance, PEDOT-PSS coated fibers experience a decrease in resistance when under high temperatures [59]. Fiber optic sensors can also be used to sense temperature changes as well as temperature sensitive inks [60].

\section{Wearable E-Textiles}

Everyday, new wearable e-textile products come to the market with different useful functionalities. Figure 4 shows three examples of commercially available textile based wearable e-textiles from three different brands. Figure 4 a shows a hat commercialized by Zeroi with bone conduction technology. With this hat, the user can listen music or answer phone calls. The bone conduction technology is seamless embedded into the hat, which avoids a bionic stigma and makes this e-textile suitable 
for outdoor activities. The sound waves bypass the eardrums, going directly to the cochlea where the sounds waves are decoded. Figure $4 \mathrm{~b}$ shows a smart sock with a foot pressure measurement technology and walking distance measurement that can be used to measure sports performance. The electronic components of this product are detachable in order to wash the textile part of the socks. The collected data is sent wirelessly to a mobile application running into a smartphone. With this e-textile, runners can see the pressure profile of the foot sole and then practice their gait cycle to achieve a better performance. Figure 4c shows an airbag jacket that can be used to prevent serious injuries when a motorcycle accident occurs. The jacket has an accelerometer that detects falls and triggers the airbag before the road impact. The airbag is inflated with a small bottle of gas that needs to be replaced when the airbag is triggered. Tests performed with the airbag jacket show that, in the case of a fall, the impact forces with the ground do not exceed $2 \mathrm{kN}$. The traditional motorcycle protecting jackets have impact forces that range from 20 to $35 \mathrm{kN}$.
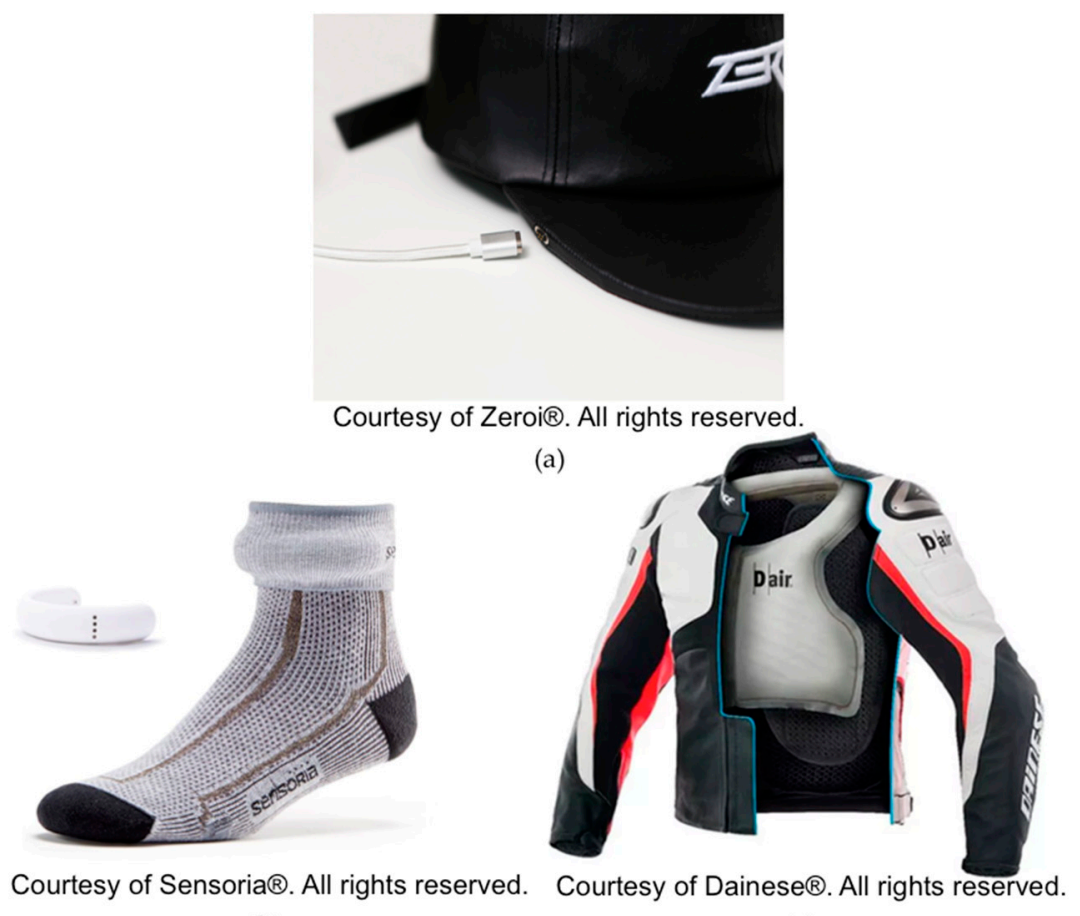

(b)

(c)

Figure 4. Wearable e-textile transducers. (a) Zeroi-Bone conduction hat [61]; (b) Sensoria-Intelligent sock with heart rate measurement system [62]; (c) D-air-Airbag jacket (motorcycling protection) [63].

Besides the commercial wearable e-textile products, there are also research projects in the medical field that aim to develop new e-textiles to improve diagnostic and treatment of several diseases. Wearable e-textiles with embedded textile electrodes are being developed to detect a variety of biological signals, such as electrocardiogram (ECG) [64] and electromyogram (EMG) [65], as well as to measure body impedance and skin conductance [66]. With the ECG detection, it is possible to do an early diagnostic of heart diseases, which can prevent sudden deaths. The EMG signal measurement is useful to evaluate physiotherapy treatment of gait cycle disorders or stroke rehabilitation [67]. The body impedance and skin conductance measurements are useful to evaluate the body hydration levels, thus helping to prevent dehydration [68]. Wearable e-textiles with functional electrical stimulation (FES) are also under development to be used in the treatment of gait disorders such as foot drop [69]. New wearable e-textiles are under development to build functional soft orthotic devices useful in the treatment of ankle-knee injuries [70]. Insomnia disorders can also be treated with wearable e-textiles able to control body temperature during sleep [71]. 


\section{Future Perspectives}

The future of wearable e-textiles will be dictated by the ability to manufacture products with seamless embedded electronics useful to fulfill daily needs. Multinational business companies are endorsing the design and development of e-textiles, helping the market penetration. At the same time, traditional textile business companies envision e-textiles production as a competitive advantage. Private users, compelled by the advantages of e-textiles, buy these products to use them in sports and daily life activities (where they can have an important role, e.g., in healthcare), thus increasing the e-textile market. The interest of business companies in the production of e-textiles together with the interest by the market creates a new e-textile cluster. This e-textile cluster will help in the development of production standards setting higher quality levels. The production standards will help decrease the e-textile manufacturing time and final fabrication costs. However, many e-textile technologies are still in the research phase where requirements such as washability, nontoxicity, and resistance to tensile strength forces still need to be addressed. The development of new standard tests to control the sources of e-textile failure, such as cyclic loads and current flow, are crucial to ensure e-textile resistance overtime. Strategies for the encapsulation of components and extension of e-textile lifetime also need to be improved. The development of e-textiles with energy harvesting features is also an important challenge to overcome. These challenges increase with higher integration levels, due to the higher number of degrees of freedom. When all of these challenges are met, e-textile mass production will become a reality, thus achieving a major milestone for these materials. New wearable e-textiles will always be both an opportunity for new markets but also a challenge to interact with conventional electronics devices.

\section{Conclusions}

The wearable e-textiles became one of the main research avenues in the textile field. The useful features that are incorporated into e-textiles bring market advantages in several areas, such as sports and healthcare. Common textile manufacturing machines and production techniques can be used to produce e-textiles. Electrical components that are used in conventional electrical circuits can also be used into e-textiles and new textile based electrical components, such as resistors, capacitors, and antennas are also being developed. Thus, the available materials and technologies provide sufficient range to be tuned and adapted for e-textiles. Wearable textile based sensors are developed in order to produce wearable seamless sensing solutions avoiding bionic stigma. Business companies already perceived the wearable e-textiles business potential and are developing e-textile products to incorporate them in their product portfolios. The wearable e-textiles are still a new field with opportunities to build innovative products that can revolutionize the way that persons interact with their garments.

Acknowledgments: The authors would like to acknowledge the support from CeNTI—Centre for Nanotechnology and Smart Materials, MIT MVL-Man Vehicle Laboratory, and UMN WTL-Wearable Technology Laboratory. This work is funded by is funded by National Funds throught FCT-Portuguese Foundation for Science and Technology, Reference UID/CTM/50025/2013 and Ph.D. grant SFRH/BD/52352/2013 (CG), MIT Portugal Program, and FEDER funds through the COMPETE 2020 Programme under the project number POCI-01-0145-FEDER007688.

Author Contributions: Carlos Gonçalves, Alexandre Ferreira da Silva, João Gomes and Ricardo Simoes contributed to the analysis of wearable e-textile technologies and the paper writing process.

Conflicts of Interest: The authors declare no conflicts of interest.

\section{References}

1. Sazonov, E.; Neuman, M.R. Wearable Sensors: Fundamentals, Implementation and Applications; Elsevier: San Diego, CA, USA, 2014.

2. Poupyrev, I.; Gong, N.-W.; Fukuhara, S.; Karagozler, M.E.; Schwesig, C.; Robinson, K.E. Project Jacquard: Interactive digital textiles at scale. In Proceedings of the $2016 \mathrm{CHI}$ Conference on Human Factors in Computing Systems, San Jose, CA, USA, 7-12 May 2016; ACM: New York, NY, USA, 2016; pp. 4216-4227. 
3. Cherenack, K.; van Pieterson, L. Smart textiles: Challenges and opportunities. J. Appl. Phys. 2012, 112, 091301. [CrossRef]

4. McLaren, R.; Joseph, F.; Baguley, C.; Taylor, D. A review of e-textiles in neurological rehabilitation: How close are we? J. Neuroeng. Rehabil. 2016, 13, 59. [CrossRef] [PubMed]

5. Helmer, R.; Blanchonette, I.; Farrow, D.; Baker, J.; Phillips, E. Interactive biomechanics and electronic textiles. In Proceedings of the 30th Annual Conference of Biomechanics in Sports, Melbourne, Australia, 2-6 July 2012.

6. Patel, S.; Park, H.; Bonato, P.; Chan, L.; Rodgers, M. A review of wearable sensors and systems with application in rehabilitation. J. Neuroeng. Rehabil. 2012, 9, 21. [CrossRef] [PubMed]

7. De Rossi, D.; Veltink, P. Wearable technology for biomechanics: E-textile or micromechanical sensors? IEEE Eng. Med. Biol. Mag. 2010, 29, 37-43. [PubMed]

8. Tognetti, A.; de Rossi, D.; Lorussi, F.; Dalle Mura, G.; Pacelli, M.; Carbonaro, N.; Paradiso, R. New generation of wearable goniometers for motion capture systems. J. Neuroeng. Rehabil. 2014, 11, 56. [CrossRef] [PubMed]

9. Shorter, K.A.; Kogler, G.F.; Loth, E.; Durfee, W.K.; Hsiao-Wecksler, E.T. A portable powered ankle-foot orthosis for rehabilitation. J. Rehabil. Res. Dev. 2011, 48, 459-472. [CrossRef] [PubMed]

10. Farina, D.; Lorrain, T.; Negro, F.; Jiang, N. High-density EMG E-textile systems for the control of active prostheses. In Proceedings of the 2010 Annual International Conference of the IEEE Engineering in Medicine and Biology Society (EMBC), Buenos Aires, Argentina, 31 August-4 September 2010; IEEE: Piscataway, NJ, USA, 2010; pp. 3591-3593.

11. Park, Y.-L.; Chen, B.-R.; Young, D.; Stirling, L.; Wood, R.J.; Goldfield, E.; Nagpal, R. Bio-inspired active soft orthotic device for ankle foot pathologies. In Proceedings of the 2011 IEEE/RSJ International Conference on Intelligent Robots and Systems (IROS), San Francisco, CA, USA, 25-30 September 2011; IEEE: Piscataway, NJ, USA, 2011; pp. 4488-4495.

12. Oess, N.P.; Wanek, J.; Curt, A. Design and evaluation of a low-cost instrumented glove for hand function assessment. J. Neuroeng. Rehabil. 2012, 9, 2. [CrossRef] [PubMed]

13. Li, H.; Yang, H.; Li, E.; Liu, Z.; Wei, K. Wearable sensors in intelligent clothing for measuring human body temperature based on optical fiber Bragg grating. Opt. Express 2012, 20, 11740-11752. [CrossRef] [PubMed]

14. Carbonaro, N.; Dalle Mura, G.; Lorussi, F.; Paradiso, R.; de Rossi, D.; Tognetti, A. Exploiting wearable goniometer technology for motion sensing gloves. IEEE J. Biomed. Health Inform. 2014, 18, 1788-1795. [CrossRef] [PubMed]

15. Rogers, J.A.; Someya, T.; Huang, Y. Materials and mechanics for stretchable electronics. Science 2010, 327, 1603-1607. [CrossRef] [PubMed]

16. Dalle Mura, G.; Lorussi, F.; Tognetti, A.; Anania, G.; Carbonaro, N.; Pacelli, M.; Paradiso, R.; de Rossi, D. Piezoresistive goniometer network for sensing gloves. In Proceedings of the XIII Mediterranean Conference on Medical and Biological Engineering and Computing 2013, Seville, Spain, 25-28 September 2013; Springer: Cham, Switzerland, 2014; pp. 1547-1550.

17. Stoppa, M.; Chiolerio, A. Wearable electronics and smart textiles: A critical review. Sensors 2014, 14, 11957-11992. [CrossRef] [PubMed]

18. Shu, L.; Hua, T.; Wang, Y.; Li, Q.; Feng, D.D.; Tao, X. In-shoe plantar pressure measurement and analysis system based on fabric pressure sensing array. IEEE Trans. Inf. Technol. Biomed. 2010, 14, 767-775. [PubMed]

19. Lee, J.; Kwon, H.; Seo, J.; Shin, S.; Koo, J.H.; Pang, C.; Son, S.; Kim, J.H.; Jang, Y.H.; Kim, D.E. Conductive fiber-based ultrasensitive textile pressure sensor for wearable electronics. Adv. Mater. 2015, 27, 2433-2439. [CrossRef] [PubMed]

20. Yun, Y.J.; Ah, C.S.; Hong, W.G.; Kim, H.J.; Shin, J.-H.; Jun, Y. Highly conductive and environmentally stable gold/graphene yarns for flexible and wearable electronics. Nanoscale 2017, 9, 11439-11445. [CrossRef] [PubMed]

21. Koc, U.; Karaca, G.Y.; Oksuz, A.U.; Oksuz, L. RF sputtered electrochromic wool textile in different liquid media. J. Mater. Sci. Mater. Electron. 2017, 28, 8725-8732. [CrossRef]

22. Preece, S.J.; Kenney, L.P.; Major, M.J.; Dias, T.; Lay, E.; Fernandes, B.T. Automatic identification of gait events using an instrumented sock. J. Neuroeng. Rehabil. 2011, 8, 32. [CrossRef] [PubMed]

23. Van der Velden, N.M.; Kuusk, K.; Köhler, A.R. Life cycle assessment and eco-design of smart textiles: The importance of material selection demonstrated through e-textile product redesign. Mater. Des. 2015, 84, 313-324. [CrossRef] 
24. Yan, L.; Yoo, J.; Kim, B.; Yoo, H.-J. A 0.5-V 12-W wirelessly powered patch-type healthcare sensor for wearable body sensor network. IEEE J. Solid-State Circuits 2010, 45, 2356-2365. [CrossRef]

25. Almusallam, A.; Luo, Z.; Komolafe, A.; Yang, K.; Robinson, A.; Torah, R.; Beeby, S. Flexible piezoelectric nano-composite films for kinetic energy harvesting from textiles. Nano Energy 2017, 33, 146-156. [CrossRef]

26. Linz, T.; von Krshiwoblozki, M.; Walter, H. Novel Packaging Technology for Body Sensor Networks Based on Adhesive Bonding A Low Cost, Mass Producible and High Reliability Solution. In Proceedings of the 2010 International Conference on Body Sensor Networks (BSN), Singapore, 7-9 June 2010; IEEE: Piscataway, NJ, USA, 2010; pp. 308-314.

27. Byrne, C.A.; Rebola, C.B.; Zeagler, C. Design research methods to understand user needs for an etextile knee sleeve. In Proceedings of the 31st ACM International Conference on Design of Communication, Greenville, NC, USA, 30 September-1 October 2013; ACM: New York, NY, USA, 2013; pp. 17-22.

28. Bhattacharya, R.; Van Pieterson, L.; Van Os, K. Improving conduction and mechanical reliability of woven metal interconnects. IEEE Trans. Compon. Packag. Manuf. Technol. 2012, 2, 165-168. [CrossRef]

29. Kallmayer, C.; Simon, E. Large area sensor integration in textiles. In Proceedings of the 20129 th International Multi-Conference on Systems, Signals and Devices (SSD), Chemnitz, Germany, 20-23 March 2012; IEEE: Piscataway, NJ, USA, 2012; pp. 1-5.

30. Karim, N.; Afroj, S.; Malandraki, A.; Butterworth, S.; Beach, C.; Rigout, M.; Novoselov, K.S.; Casson, A.J.; Yeates, S.G. All inkjet-printed graphene-based conductive patterns for wearable e-textile applications. J. Mater. Chem. C 2017, 5, 11640-11648. [CrossRef]

31. Cameron, M.H. The walkaide ${ }^{\circledR}$ functional electrical stimulation system-A novel therapeutic approach for foot drop in central nervous system disorders. US Neurol. 2010, 6, 112-114. [CrossRef]

32. Make. Body Boards-A Guide to Wearable Microcontrollers. Available online: https://makezine.com/2015/ 01/28/body-boards/ (accessed on 2 March 2018).

33. Kim, Y.; Kim, H.; Yoo, H.-J. Electrical characterization of screen-printed circuits on the fabric. IEEE Trans. Adv. Packag. 2010, 33, 196-205.

34. Du, D.; Tang, Z.; Ouyang, J. Highly washable e-textile prepared by ultrasonic nanosoldering of carbon nanotubes onto polymer fibers. J. Mater. Chem. C 2018, 6, 883-889. [CrossRef]

35. Patel, S.; Hughes, R.; Hester, T.; Stein, J.; Akay, M.; Dy, J.G.; Bonato, P. A novel approach to monitor rehabilitation outcomes in stroke survivors using wearable technology. Proc. IEEE 2010, 98, 450-461. [CrossRef]

36. Prajapati, S.K.; Gage, W.H.; Brooks, D.; Black, S.E.; McIlroy, W.E. A novel approach to ambulatory monitoring: Investigation into the quantity and control of everyday walking in patients with subacute stroke. Neurorehabil. Neural Repair 2011, 25, 6-14. [CrossRef] [PubMed]

37. Park, Y.-L.; Chen, B.-R.; Majidi, C.; Wood, R.J.; Nagpal, R.; Goldfield, E. Active modular elastomer sleeve for soft wearable assistance robots. In Proceedings of the 2012 IEEE/RSJ International Conference on Intelligent Robots and Systems (IROS), Vilamoura-Algarve, Portugal, 7-11 October 2012; IEEE: Piscataway, NJ, USA, 2012; pp. 1595-1602.

38. Post, E.R.; Orth, M.; Russo, P.; Gershenfeld, N. E-broidery: Design and fabrication of textile-based computing. IBM Syst. J. 2000, 39, 840-860. [CrossRef]

39. Giorgino, T.; Tormene, P.; Maggioni, G.; Capozzi, D.; Quaglini, S.; Pistarini, C. Assessment of sensorized garments as a flexible support to self-administered post-stroke physical rehabilitation. Eur. J. Phys. Rehabil. Med. 2009, 45, 75-84. [PubMed]

40. Lilja, J.; Salonen, P. Making flexible resistors out of conductive polymer fabrics. Electron. Lett. 2011, 47, 602-604. [CrossRef]

41. Kumar, B.; Kaushik, B.K.; Negi, Y.S. Organic thin film transistors: Structures, models, materials, fabrication, and applications: A review. Polym. Rev. 2014, 54, 33-111. [CrossRef]

42. Zysset, C.; Kinkeldei, T.W.; Munzenrieder, N.; Cherenack, K.; Troster, G. Integration method for electronics in woven textiles. IEEE Trans. Compon. Packag. Manuf. Technol. 2012, 2, 1107-1117. [CrossRef]

43. Paul, G.; Torah, R.; Beeby, S.; Tudor, J. Novel active electrodes for ECG monitoring on woven textiles fabricated by screen and stencil printing. Sens. Actuators A Phys. 2015, 221, 60-66. [CrossRef]

44. Avloni, J.; Lau, R.; Ouyang, M.; Florio, L.; Henn, A.; Sparavigna, A. Polypyrrole-coated nonwovens for electromagnetic shielding. J. Ind. Text. 2008, 38, 55-68. [CrossRef] 
45. Komolafe, A.; Torah, R.; Tudor, J.; Beeby, S. Improving the durability of screen printed conductors on woven fabrics for e-textile applications. Proceedings 2017, 1, 613. [CrossRef]

46. Yip, M.C.; Niemeyer, G. High-performance robotic muscles from conductive nylon sewing thread. In Proceedings of the 2015 IEEE International Conference on Robotics and Automation (ICRA), Seattle, WA, USA, 26-30 May 2015; IEEE: Piscataway, NJ, USA, 2015; pp. 2313-2318.

47. Shen, L.; Healy, N.; Xu, L.; Cheng, H.; Day, T.; Price, J.; Badding, J.; Peacock, A. Four-wave mixing and octave-spanning supercontinuum generation in a small core hydrogenated amorphous silicon fiber pumped in the mid-infrared. Opt. Lett. 2014, 39, 5721-5724. [CrossRef] [PubMed]

48. Castano, L.M.; Flatau, A.B. Smart fabric sensors and e-textile technologies: A review. Smart Mater. Struct. 2014, 23, 053001. [CrossRef]

49. Stewart, R.; Skach, S. Initial Investigations into Characterizing DIY E-Textile Stretch Sensors. In Proceedings of the 4th International Conference on Movement Computing, London, UK, 28-30 June 2017; ACM: New York, NY, USA, 2017.

50. Hill, K.; Malo, B.; Bilodeau, F.; Johnson, D. Photosensitivity in optical fibers. Annu. Rev. Mater. Sci. 1993, 23, 125-157. [CrossRef]

51. Silvestri, S.; Schena, E. Optical-Fiber Measurement Systems for Medical Applications; InTech: Rijeka, Croatia, 2011.

52. Roriz, P.; Ramos, A.; Santos, J.L.; Simões, J.A. Fiber optic intensity-modulated sensors: A review in biomechanics. Photon. Sens. 2012, 2, 315-330. [CrossRef]

53. Brochu, P.; Pei, Q. Dielectric Elastomers for Actuators and Artificial Muscles. In Electroactivity in Polymeric Materials; Springer: New York, NY, USA, 2012; pp. 1-56.

54. Gracies, J.-M.; Marosszeky, J.E.; Renton, R.; Sandanam, J.; Gandevia, S.C.; Burke, D. Short-term effects of dynamic lycra splints on upper limb in hemiplegic patients. Arch. Phys. Med. Rehabil. 2000, 81, 1547-1555. [CrossRef] [PubMed]

55. Pu, X.; Li, L.; Liu, M.; Jiang, C.; Du, C.; Zhao, Z.; Hu, W.; Wang, Z.L. Wearable self-charging power textile based on flexible yarn supercapacitors and fabric nanogenerators. Adv. Mater. 2016, 28, 98-105. [CrossRef] [PubMed]

56. Ma, X.; Li, Y.; Wang, W.; Ji, Q.; Xia, Y. Temperature-sensitive poly (N-isopropylacrylamide)/graphene oxide nanocomposite hydrogels by in situ polymerization with improved swelling capability and mechanical behavior. Eur. Polym. J. 2013, 49, 389-396. [CrossRef]

57. Kinkeldei, T.; Zysset, C.; Cherenack, K.; Tröster, G. A textile integrated sensor system for monitoring humidity and temperature. In Proceedings of the 2011 16th International Solid-State Sensors, Actuators and Microsystems Conference (TRANSDUCERS), Beijing, China, 5-9 June 2011; IEEE: Piscataway, NJ, USA, 2011; pp. 1156-1159.

58. Jeong, S.H.; Cruz, F.J.; Chen, S.; Gravier, L.; Liu, J.; Wu, Z.; Hjort, K.; Zhang, S.-L.; Zhang, Z.-B. Stretchable Thermoelectric Generators Metallized with Liquid Alloy. ACS Appl. Mater. Interfaces 2017, 9, 15791-15797. [CrossRef] [PubMed]

59. Lay, M.; Pèlach, M.À.; Pellicer, N.; Tarrés, J.A.; Bun, K.N.; Vilaseca, F. Smart nanopaper based on cellulose nanofibers with hybrid PEDOT: PSS/polypyrrole for energy storage devices. Carbohydr. Polym. 2017, 165, 86-95. [CrossRef] [PubMed]

60. Witt, J.; Narbonneau, F.; Schukar, M.; Krebber, K.; De Jonckheere, J.; Jeanne, M.; Kinet, D.; Paquet, B.; Depre, A.; D'Angelo, L.T. Medical textiles with embedded fiber optic sensors for monitoring of respiratory movement. IEEE Sens. J. 2012, 12, 246-254. [CrossRef]

61. 2XU. Smart Hat. Available online: http://www.2xu.com/us/p/smart-hat/UQ4194f.html (accessed on 2 March 2018).

62. Sensoria. Sensoria Smart Socks-A Better Way to Run. Available online: http:/ /www.sensoriafitness.com/ (accessed on 2 March 2018).

63. Dainese. D-Air. Available online: https://www.dainese.com/ (accessed on 2 March 2018).

64. Jin, H.; Matsuhisa, N.; Lee, S.; Abbas, M.; Yokota, T.; Someya, T. Enhancing the performance of stretchable conductors for e-textiles by controlled ink permeation. Adv. Mater. 2017, 29. [CrossRef] [PubMed]

65. Niijima, A.; Isezaki, T.; Aoki, R.; Watanabe, T.; Yamada, T. hitoeCap: Wearable EMG sensor for monitoring masticatory muscles with PEDOT-PSS textile electrodes. In Proceedings of the 2017 ACM International Symposium on Wearable Computers, Maui, Hawaii, 11-15 September 2017; ACM: New York, NY, USA, 2017; pp. 215-220. 
66. Majidi, C. Artificial skin: Soft electronics \& sensors for bio-inspired robots and wearable computing. Mech. Eng. 2016, 138, S17-S21.

67. Wang, Q.; Markopoulos, P.; Yu, B.; Chen, W.; Timmermans, A. Interactive wearable systems for upper body rehabilitation: A systematic review. J. Neuroeng. Rehabil. 2017, 14, 20. [CrossRef] [PubMed]

68. Paradiso, R.; Caldani, L.; Pacelli, M. Knitted electronic textiles. In Wearable Sensors; Elsevier: Cambridge, MA, USA, 2015; pp. 153-174.

69. Agrawal, D.P. Personal/body area networks and healthcare applications. In Embedded Sensor Systems; Springer: Singapore, 2017; pp. 353-390.

70. Pettys-Baker, R.; Compton, C.; Utset-Ward, S.; Tompkins, M.; Holschuh, B.; Dunne, L.E. Design and development of valgus-sensing leggings. In Proceedings of the 2017 Design of Medical Devices Conference, Minneapolis, MN, USA, 10-13 April 2017; American Society of Mechanical Engineers: New York, NY, USA, 2017; p. V001T005A017.

71. Zavrel, E.A.; Ebben, M.R. An active distal limb warming device for insomnia treatment. In Proceedings of the 2017 Design of Medical Devices Conference, Minneapolis, MN, USA, 10-13 April 2017; American Society of Mechanical Engineers: New York, NY, USA, 2017; p. V001T011A013.

(C) 2018 by the authors. Licensee MDPI, Basel, Switzerland. This article is an open access article distributed under the terms and conditions of the Creative Commons Attribution (CC BY) license (http://creativecommons.org/licenses/by/4.0/). 